\title{
New research leads to end of blood ban
}

$\mathrm{M}$ en who have sex with men will soon be permitted to donate blood in Canada, following a May 22 Health Canada decision, based on new data, to lift a 25-year-old ban.

The lifetime ban will be lifted, and men who have not had sex with a man in the last five years will be eligible. The change to the law, expected to come into effect in July, was proposed by blood operators Canadian Blood Services (CBS) and Héma-Québec (HQ).

Both organizations conducted research and came to the conclusion that the risk of HIV transmission from blood donation does not increase after a five-year abstinence period for men who have sex with men. Approximately 31330 of these men are HIV-positive, making them the largest subpopulation of HIV-infected people in the country (www.cmaj.ca /lookup/doi/10.1503/cmaj.091476).

The new research is based on modelling techniques that had not been previously conducted. Previously, Health Canada had only been presented with population data, which does not account for theoretical scenarios. The new data, generated by using the Monte Carlo method, allows researchers to assess risk differently.

The technique takes into account risk-probability across a wide spectrum, including extreme and typical clinical scenarios. It concluded that removal of the ban would mean the already-low chance of contracting HIV through blood transfusion (estimated at 1 in 30 million in Quebec) would remain the same. As a result, reduction of the ban will open up the opportunity for thousands of new donors.

"We've only seen longitudinal data as far up to as 2010, where we felt that there was insufficient evidence to consider reducing the ban," says Dr. Robert
Cushman, director general of Health Canada's Biologics and Genetic Therapies Directorate.

In 2012, CBS and HQ presented evidence using newly applied statistical techniques: the Monte Carlo method. "The new data were very convincing, and reducing the ban from permanent to

about social justice, but mainly about safety," says Dr. Dana Devine, vice president of medical, scientific and research affairs at CBS. The representatives agreed on a five-year deferral ban following presentation of the new data, reviewed by the scientific expert panel.

Many believe that implementation of the temporary ban will make minimal difference to blood donations in practice. But others are more optimistic. "In Canada, approximately 122000 men will now be eligible to donate blood," says Dr. Marc Germain, vice president of medical affairs at $\mathrm{HQ}$.

This is the number of men who have had sex with another man, but not in the last five years. "Knowing that approximately $4 \%$ of the general population donates blood, Canada could see an additional 4530 blood donors as a result of this change," he added.

And where to next? CBS predicts that a combination of evolving data and new technologies involving pathogen-reduction techniques will allow us to consider further reducing the deferral period for men who have sex with men. Additionally, such techniques may open up the doors for people who have historically been excluded from donating to give blood, such as hepatitis carriers and those previously infected with West Nile virus.

Health Canada recognizes that this may only be the first step of a long process. "This is an iterative process, and testing will become even more effective," says Cushman.

Safety is the main priority, according to the regulatory body and both blood operators. With respect to the backlash from critics who think the deferral is still discriminatory and not enough, Cushman suggests that further changes are possible. "It's not over," he says. "It's not final." - Neil Chanchlani, CMAJ

CMAJ 2013. DOI:10.1503/cmaj.109-4509 